\title{
Evaluation and characterization of the symbiotic effect of benzylidene derivative with titanium dioxide nanoparticles on the inhibition of the chemical corrosion of mild steel
}

\author{
S.S. Al-Taweel, ${ }^{1}$ K.W.S. Al-Janabi, ${ }^{2}$ H.M. Luaibi, ${ }^{3}$ A.A. Al-Amiery ${ }^{4 *}$ \\ and T.S. Gaaz ${ }^{*}$
}

${ }^{1}$ University of Al-Qadisiyah, College of Science, Department of Chemistry, Dewaniyah, Iraq

${ }^{2}$ University of Baghdad, College of Education for Pure Sciences/Ibn Al-Haitham, Chemistry department, Baghdad 10053, Iraq

${ }^{3}$ Al-Karkh University of Science, College of Science of Energy and Environment, Baghdad, Iraq

${ }^{4}$ Energy and Renewable Energies Technology Center, University of Technology, Baghdad 10001, Iraq

${ }^{5}$ Technical College Al-Musaib, Al-Furat Al Awsat Technical University, Al-Musaib, Babil 51009, Iraq

*E-mail: dr.ahmed1975@gmail.com; taysersumer@atu.edu.iq

\begin{abstract}
A new benzylidene derivative, namely $N$-benzylidene-5-phenyl-1,3,4-thiadiazol-2-amine (BPTA), has been synthesized and instrumentally confirmed with Elemental Analysis (CHN), Nuclear Magnetic Resonance (NMR), and Fourier Transform Infrared Spectroscopy (FT-IR). Titanium Dioxide $\left(\mathrm{TiO}_{2}\right)$ nanoparticles (NPs) were synthesized and characterized by X-ray. The mutualistic complementary dependence of BPTA with $\mathrm{TiO}_{2}$ nanoparticles as anticorrosive inhibitor on mild steel (MS) in $1.0 \mathrm{M}$ hydrochloric acid has been tested at various concentrations and various temperatures. The methodological work was achieved by gravimetric measurement methods complemented with surface analysis. The synthesized inhibitor concentrations were $0.1 \mathrm{mM}$ to $0.5 \mathrm{mM}$ and the temperatures ranging from 303$333 \mathrm{~K}$. The BPTA with $\mathrm{TiO}_{2}-\mathrm{NP}$ as a synergistic inhibitor becomes superior inhibitive effects with more than $96 \%$ inhibition competence of MS coupons in a harsh acidic medium. The efficiency of the inhibition improved with increasing BPTA content and also increase with the Synergistic effects of BPTA with $\mathrm{TiO}_{2}-\mathrm{NP}$. The excellent effectiveness was performed with the $0.5 \mathrm{mM}$ concentration of BPTA and become higher with adding of $\mathrm{TiO}_{2}-\mathrm{NP}$ rising to the maximum inhibition efficiency (IE). However, the inhibition efficacy declined as the temperature rises. Results of BPTA as corrosion inhibitor indicated the obedience of the adsorption of the inhibitor of mixed type on the surface of MS to Langmuir adsorption isotherm. It was found that the BPTA and performance depend on the Synergistic effects, concentrations of the $\mathrm{TiO}_{2}-\mathrm{NP}$ and $\mathrm{BPTA}$, in addition to the solution temperature. Nevertheless, the quantum calculations have confirmed the direct correlation of the electronic characteristics of BPTA with the corrosive inhibitive influence.
\end{abstract}


Keywords: mild steel, $\mathrm{TiO}_{2}$, inhibition efficiency, corrosion inhibitor, benzylidene.

Received: December 14, 2019. Published: December 25, 2019

doi: $\underline{10.17675 / 2305-6894-2019-8-4-21}$

\section{Introduction}

In developing countries, there is a common problem in the industry that causes huge economic losses caused due to corrosion. Mild steel demonstrates a weak corrosion impedance toward corrosive solutions especially hydrochloric acid. Mild steel was extensively used in oil and gas and allied industries. Rod and plates of MS were, utilized in bridges, buildings, pipelines, vehicles, and ships in addition to numerous other employments [1]. Hydrochloric acid is corrosive to MS and most other alloys [2]. Conversely, organic molecules with heteroatoms like sulfur, nitrogen, oxygen, and phosphorous were successfully utilized as corrosion inhibitors [3]. These organic molecules have electron density enables them to form a protective layer on metallic surfaces [4]. Nowadays, the employ of pharmaceuticals and chemicals were studied and the inhibitive activities were related to the heterocyclic nature [5]. The individual advantage of utilizing natural molecules and some organic compounds for the inhibitive of the corrosive of alloys are which are eco-friendly [6]. Most heterocyclic organic compounds are eco-friendly and could favorably contest with the natural molecules. A carbon-nitrogen double bond is a covalent bond between carbon and nitrogen and is one of the most considerable bonds in organic chemistry and natural products. Schiff bases, having the $\mathrm{C}=\mathrm{N}$ bond, are synthesized by the reaction of amine (primary) and carbonyl compounds [7]. Schiff bases were applied widely in pharmaceutical, and medicinal areas [8]. In general Schiff bases with aromatic ring usually have perfect bio-applications [9]. Following up on the investigations for active corrosive inhibitors for steel alloy in acidic media[ 10-32], this investigation reports the synergistic inhibitive effects of BPTA and $\mathrm{TiO}_{2}$-NP towards $\mathrm{MS}$ corrosion in a $1 \mathrm{M}$ solution of hydrochloric acid, that were not published previously. BPTA and $\mathrm{TiO}_{2}-\mathrm{NP}$ are both easy to synthesized, eco-friendly and cheap. Weight loss method has been used to evaluate the IE. In addition, quantum chemical calculations have been done to support the methodological results.

\section{Experimental}

\subsection{Instrumentation and Materials}

Most chemicals were from Sigma Aldrich Malaysia. UV-1800 spectrometer, Shimadzu, Japan. Carlo Erba 5500 CHN elemental analyzer. FTIR-8300 spectrometer, Shimadzu, Japan.

Nuclear magnetic resonance spectrometer (NMR), Bruker $300 \mathrm{MHz}$ Spectrospin instrument. 


\subsection{Synthesis of 5-phenyl-1,3,4-thiadiazol-2-amine}

Benzoic acid $(5.00 \mathrm{mmol})$ was mixed with thiosemicarbazide $(5.00 \mathrm{mmol})$ in the presence of $30 \mathrm{ml}$ of concentrated sulfuric acid and refluxed for 7 hours. The reaction progress was followed up by TLC. Upon reaction equilibrium, the resulting mixture was poured into an ice bath and then basified using a concentrated solution of ammonium hydroxide. On a water bath, the residuals were dissolved in ethanol and hot water was gradually added with stirring. Then left a side to cool down to room temperature and dried over phosphorus pentoxide under vacuum for 24 hours. The developed solid product was dissolved in chloroform: methanol $(8: 2 \mathrm{v} / \mathrm{v})$ and purified over a column of silica gel. Recrystallization of the eluent produces 5-phenyl-1,3,4-thiadiazol-2-amine powder. The properties of the resultant powder were as follows: melting point $225^{\circ} \mathrm{C}$, yield $40 \%$, FT-IR $\left(v_{\max }, \mathrm{cm}^{-1}\right)$ : 3270 for $(\mathrm{NH}) ; 3100$ (aromatic $\mathrm{C}-\mathrm{H}) ; 700\left(\mathrm{C}-\mathrm{S}\right.$ stretching); $1630(\mathrm{C}=\mathrm{N}) ;{ }^{1} \mathrm{H}$ NMR: $\delta$

(ppm) $5.17\left(\mathrm{H}, \mathrm{s}, \mathrm{NH}_{2}\right), 7.37-7.02(\mathrm{H}, \mathrm{m}, \mathrm{Ar}-\mathrm{H}),{ }^{13} \mathrm{C}$ NMR: $\delta$ (ppm) 128.1, 129.1, 130.4 and 132.1 for (carbon benzene ring), 162.7, 169.2 (carbon thiadiazole ring), anal. Calculated/Found for $\mathrm{C}_{8} \mathrm{H}_{7} \mathrm{~N}_{3} \mathrm{~S}: \mathrm{C}, 54.22 / 53.96, \mathrm{H}, 3.98 / 4.03, \mathrm{~N}, 23.71 / 24.03$.

\subsection{Synthesis of BPTA as a corrosive inhibitor}

An ethanolic solution of equimolar quantities of benzaldehyde and 2-amino-5-phenyl1,3,4-thiadiazol $(0.01 \mathrm{~mol})$ was refluxed on a water bath for $5 \mathrm{hrs}$. The resulting compound BPTA precipitated on cooling, was then filtered and purified by recrystallization from ethanol to obtain the BPTA. M.p. $169.5^{\circ} \mathrm{C}$, Yield $88 \%$, FT-IR spectrum $\left(v, \mathrm{~cm}^{-1}\right): 1570$ $(\mathrm{C}=\mathrm{N}) ;{ }^{1} \mathrm{H}$ NMR $\left(\mathrm{CDCl}_{3}-\mathrm{DMSO}-\mathrm{d}_{6}, \delta, \mathrm{ppm}\right): 8.82(\mathrm{~s}, 1 \mathrm{H}$, azomethine $\mathrm{CH}=\mathrm{N}), 7.36,7.55$, 7.59, 7.93 and 8.01, (10H aromatic $\mathrm{H}) ;{ }^{13} \mathrm{C}$ NMR $\left(\mathrm{CDCl}_{3}-\mathrm{DMSO}-\mathrm{d}_{6}, \delta, \mathrm{ppm}\right): 173.10$ and 174.11 (carbon for thiadiazole ring); $164.31(\mathrm{CH}=\mathrm{N}) ; 128.8,129.76,131.26,134.75$, $128.39,127.38,132.41,137.16$ (carbon for aromatic rings). Anal. Calculated/found for $\mathrm{C}_{15} \mathrm{H}_{11} \mathrm{~N}_{3} \mathrm{~S}: \mathrm{C}, 67.90 / 68.10, \mathrm{H}, 4.18 / 4.14, \mathrm{~N}, 15.84 / 15.63$.

\subsection{Synthesis of $\mathrm{TiO}_{2}-\mathrm{NP}$}

Titanium dioxide $\left(\mathrm{TiO}_{2}\right)$ was prepared by the sol-gel method [33]. A solvent mixture of $30 \mathrm{ml}$ absolute ethanol, $1 \mathrm{ml}$ acetone, and $2 \mathrm{ml}$ acetic acid was used to dissolve $1 \mathrm{~mol}$ of $\mathrm{TiCl}_{4}$ and $4 \mathrm{~mol}$ of $\left(\mathrm{HOC}_{4} \mathrm{H}_{9}\right)$. The mixture was shaken in the dark for $30 \mathrm{~min}$, then extended for another $2 \mathrm{hrs}$ to be filtered and dried at $550^{\circ} \mathrm{C}$.

\subsection{Steel samples}

Mild Steel (MS) that had the composition (wt.\%) of "99.21 Fe, 0.21 C, 0.38 Si, 0.09 P, $0.05 \mathrm{~S}, 0.05 \mathrm{Mn}$, and $0.01 \mathrm{Al}$ " was cut into the dimensions of $3 \times 3 \times 1 \mathrm{~cm}$. They were cleaned using silicon carbide paper, sonicated for fifteen minutes with ethyl alcohol, washed with distilled water, acetone and dried. 


\subsection{Corrosive environment}

Corrosion investigations were carried out into a strongly acidic environment composed of 1.0 M hydrochloric acid.

\subsection{Preparing the inhibitor}

A set of the synthesized corrosion inhibitor BPTA was prepared [34] in the concentrations of $0.1,0.2,0.3,0.4$ and $0.5 \mathrm{mM}$.

\subsection{Gravimetric Analysis}

The weight loss technique was carried out following ASTM procedure for metal corrosion testing [34,35]. MS samples were immersed in the corrosive environment in the presence and absence of various concentrations of the synthesized inhibitor BPTA. The concentration optimization of the BPTA was carried out in $5 \mathrm{~h}$ period. The synergistic impact was investigated with the addition of $0.001 \mathrm{~g}$ of $\mathrm{TiO}_{2}-\mathrm{NP}$. The impact of immersion time was carried out between $1 \mathrm{~h}, 5 \mathrm{~h}, 10 \mathrm{~h}$, and $24 \mathrm{~h}$, the process was performed at room temperature. The temperature was stabilized through a water bath. The specimens were weighed after immersion into the electrolyte. The specimens were taken out after a specified period, cleaned and weighed. For temperature investigations, the same procedure was repeated and the immersion time was five hours. Corrosion rate $C_{\mathrm{R}}, I E$, and surface coverage $(\theta)$ were calculated by the equations 1 to 3 .

$$
C_{\mathrm{R}}=\frac{87.6 \times W}{t \times A \times d}
$$

where $W$ is the MS mass loss (gram), $t$ is the immersion time, $d$ is the density and $A$ is the area.

$$
\begin{gathered}
I E=\frac{C_{\mathrm{R} 0}-C_{\mathrm{Rin}}}{C_{\mathrm{R} 0}} \times 100 \\
\theta=C_{\mathrm{R} 0}-\frac{C_{\mathrm{Rin}}}{C_{\mathrm{R} 0}}
\end{gathered}
$$

where $C_{\mathrm{R} 0}$ and $C_{\mathrm{Rin}}$ are the corrosion rates in the absence and presence of the BPTA, respectively.

\subsection{Calculation methods}

Density functional theory [36] (DFT) has been employed in this study. Recently DFT has become quite popular since it can reach accuracy comparable to other computational calculations. Computational calculations were completed through GAUSSIAN 03W software [37], applying B3LYP functional [38,39] with a $6-31 \mathrm{G}$ basis set [41]. The B3LYP, a version of DFT, applied Beche's three-parameter functional along with the LeeYang-Paar correlation functional $[37,40]$. This technique is demonstrated to produce 
optimized geometries. The obtained frontier molecular orbital energies such as $E_{\mathrm{HO} о}$ and $E_{\mathrm{LUMO}}$ help workout significant factors [8] like $\Delta E, \sigma, \eta, \chi$, and $\Delta N$ using equations (4-8)

$$
\begin{gathered}
\Delta E=E_{\mathrm{HOMO}}-E_{\mathrm{LUMO}} \\
\eta=-\frac{1}{2}\left(E_{\mathrm{HOMO}}-\mathrm{E}_{\mathrm{LUMO}}\right) \\
\sigma=\frac{1}{\eta} \\
\chi=-\frac{1}{2}\left(E_{\mathrm{HOMO}}+E_{\mathrm{LUMO}}\right) \\
\Delta N=-\frac{\chi_{\mathrm{Fe}}-\chi_{\mathrm{inh}}}{2\left(\eta_{\mathrm{Fe}}+\eta_{\text {inh }}\right)}
\end{gathered}
$$

where $\chi_{\mathrm{Fe}}$ and $\eta_{\text {inh }}$ represent the electronegativity and hardness of $\mathrm{Fe}$ and the inhibitor, respectively.

For $\chi_{\mathrm{Fe}}$, reported amount of $7 \mathrm{eV} / \mathrm{mol}$ have been used, but for the $\mathrm{Fe}, \eta_{\mathrm{Fe}}, 0 \mathrm{eV} / \mathrm{mol}$ have been utilized [41]. Nowadays literature reveals that the theoretically chosen value of $\chi_{\mathrm{Fe}}$ equal to seven electron volt was not acceptable because of omission of electronelectron interaction and only free electron gas Fermi energy of iron is taken into account. Therefore, to avoid this anomaly, the work function $(\phi)$ of the metal surface is used in place of $\chi_{\mathrm{Fe}}$, equation (9).

$$
\Delta N=-\frac{\phi-\chi_{\mathrm{inh}}}{2\left(\eta_{\mathrm{Fe}}+\eta_{\mathrm{inh}}\right)}
$$

\section{Results and Discussion}

\subsection{Chemistry}

Sequences of reaction for the benzylidene derivative synthesis were starting from low cost starting material thiosemicarbazide (Scheme 1). 2-Amino-5-phenyl-1,3,4-thiadiazole was obtained by refluxing benzoic acid with thiosemicarbazide in concentrated sulfuric acid as a dehydrator [22] The FT-IR spectrum of this compound showed an absorption band at $3270 \mathrm{~cm}^{-1}\left(\mathrm{~N}-\mathrm{H}\right.$ amine stretching) and $1630 \mathrm{~cm}^{-1}$ (azomethine $\left.\mathrm{C}=\mathrm{N}\right)$. The ${ }^{1} \mathrm{H}$ NMR spectrum exhibited a singlet at $\delta 5.17 \mathrm{ppm}$ due to the two $\mathrm{NH}_{2}$ protons. The reaction of 5phenyl-1,3,4-thiadiazole-2-amine with benzaldehyde afforded benzylidene namely BPTA in good yield. The FT-IR spectrum of compound BPTA showed absorption bands at $1570 \mathrm{~cm}^{-1}$ (azomethine $\mathrm{C}=\mathrm{N}$ ). The ${ }^{1} \mathrm{H}$ NMR spectrum exhibited a singlet at $\delta 8.82 \mathrm{ppm}$ due to the one azomethine proton and multiplet due to the aromatic proton at $\delta 7.36,7.55$, $7.59,7.93$ and $8.01 \mathrm{ppm}$. 


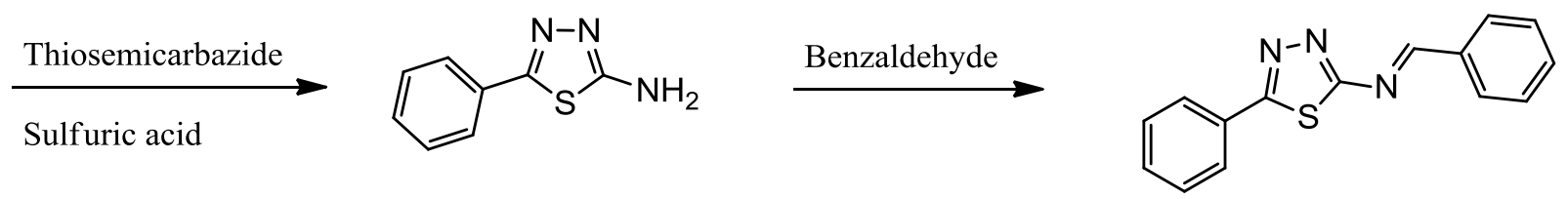

Scheme 1. The chemical structure of the BPTA.

\subsection{Gravimetric techniques}

\subsubsection{Effects of concentrations}

For years, the decay of MS in a corrosive environment was considered as a form of an electrochemical reaction. Such electrochemical reactions, as well as the high dissolution of the corrosive products, resulted in a weight loss of MS [42].

The corrosive inhibitive efficiency of BPTA against steady corrosion had been studied by monitoring the weight loss as the processes occur. The inhibition activity was measured from CR (corrosion rate) as in equations (1 and 2), however surface coverage as in equation (3). The weight loss of MS has been calculated without and with BPTA. The IE of the MS has been studied thoroughly by immersion of MS samples in different concentrations of BPTA. The test shows an increase of the IE with the increase of BPTA concentration (Figure 1). Such behavior may be attributed to the adsorption sites on BPTA structure.

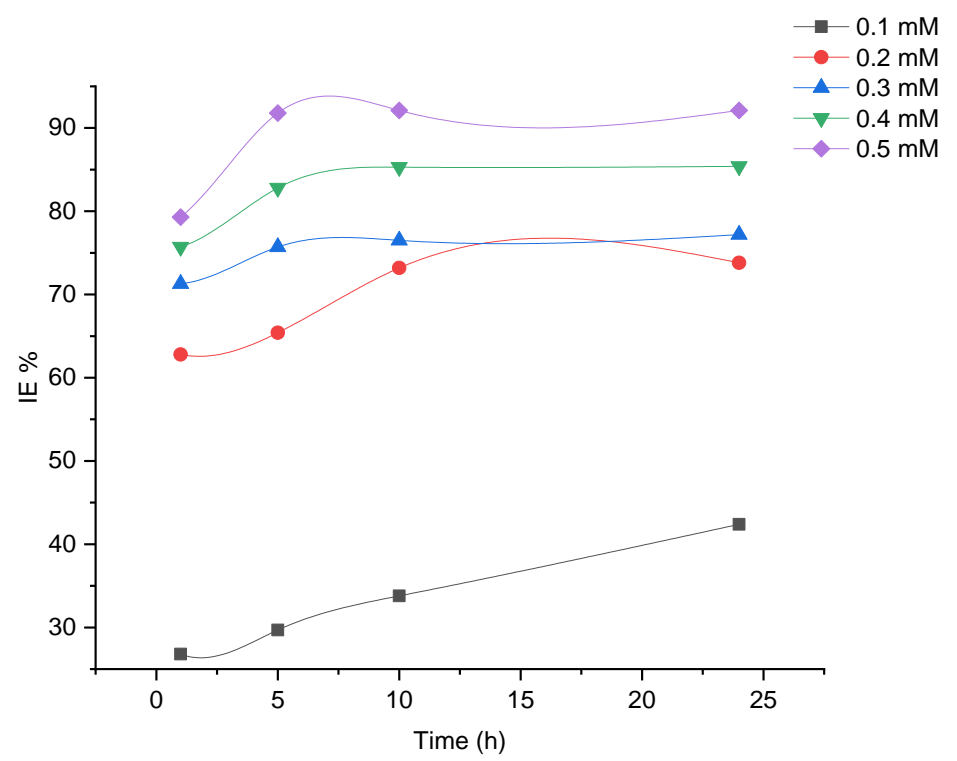

Figure 1. Immersion time impact of MS in a corrosive environment at various concentrations of BPTA.

Likewise, the synergistic effect of benzylidene with $\mathrm{TiO}_{2}-\mathrm{NP}$ on the corrosion inhibition of MS in a corrosive environment was studied as a function of IE (Figure 2). The IE increases with the increase in the concentration of the BPTA due to adsorption sites in the structure of the studied BPTA and $\mathrm{TiO}_{2}-\mathrm{NP}$. 


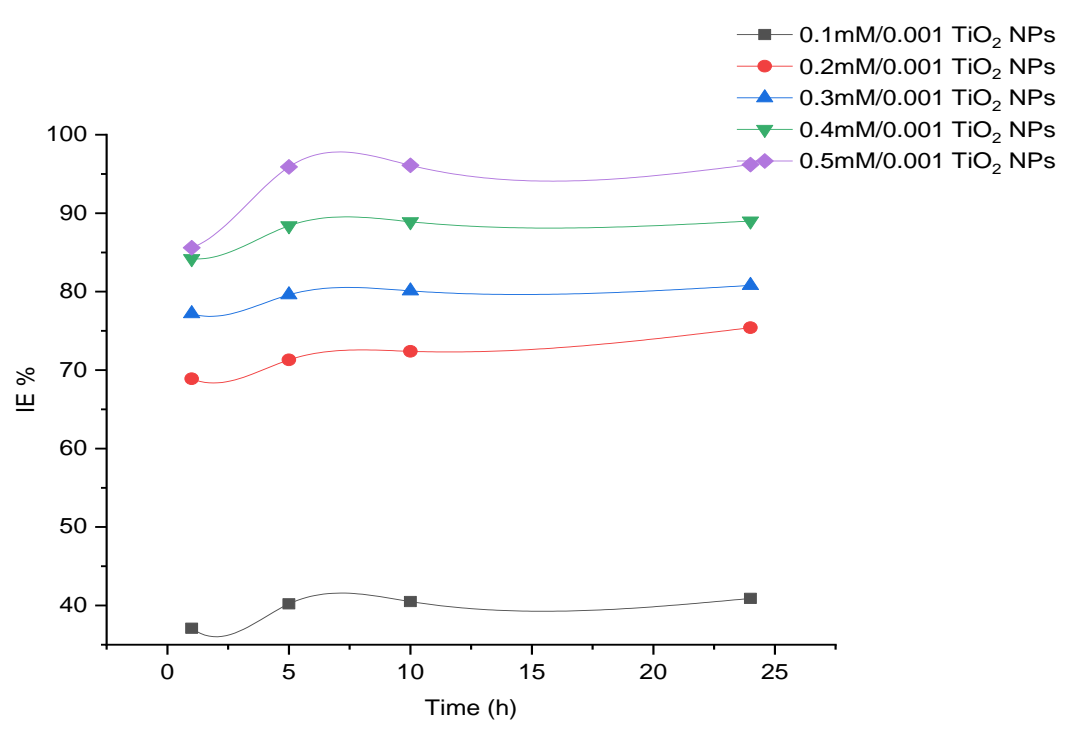

Figure 2. Immersion time impact of MS in a corrosive environment at various concentrations of BPTA synergistic with $0.001 \mathrm{~g}$, of $\mathrm{TiO}_{2}$-NPs.

The maximum IE of $92 \%$ for BPTA and it was $96 \%$ in presence of $\mathrm{TiO}_{2}-\mathrm{NP}$ were obtained at the optimum concentration of $5 \mathrm{mM}$ at 5 to $10 \mathrm{~h}$, attributed to the availability of $\mathrm{N}$ and $\mathrm{S}$ atoms in addition to aromatic rings (aryl and 1,3,4-thiadiazole) in the molecule structure which participate in the inhibitive activities as active sites and electrostatically forces between BPTA molecules with the surface of MS. These heteroatoms react with the surface of the studied alloy through adsorption or coordination and increasing inhibition efficiencies. Also, the $\mathrm{TiO}_{2}-\mathrm{NP}$ molecules increase the $\mathrm{IE}$, thus, the effect of $\mathrm{TiO}_{2}-\mathrm{NP}$ molecules withdraws electrons from aromatic rings by resonance effect. The results clearly indicated that BPTA, molecules reduce the corrosion rate of MS in both cases with and without of $\mathrm{TiO}_{2}$-NP.

\subsubsection{Immersion time impact}

Time is a considerable parameter when describing the corrosive inhibitor molecules. Immersion time was investigated in order to determine the inhibitor film stability and adsorption rate. The time of immersion was changed from 1 to 24 hours. Results were demonstrated in Figures 1 and 2 which indicated the influence of immersion time on inhibition efficiencies of BPTA in absence and presence $\mathrm{TiO}_{2}-\mathrm{NP}$ respectively. From Figure 1, the highest corrosion inhibitive activity was attained at the early period of immersion that was $5-10 \mathrm{~h}$, because of the fast adsorption of the BPTA molecules on to MS surface due to the maximum numbers of available active inhibitor molecules to inhibit MS from corrosion. From Figure 2, after $5 \mathrm{~h}$ to $24 \mathrm{~h}$, of immersion time no significant differences due to the presence of $\mathrm{TiO}_{2}-\mathrm{NP}$ synergistic with BPTA molecules. Without synergistic effects (in absence of $\mathrm{TiO}_{2}-\mathrm{NP}$ ) the IE observes to reduce after ten hours of immersion. After the $24 \mathrm{~h}$ of immersion, the IE was further decreased. The decrease in IE 
was attributed to the desorption of BPTA, molecules from the surface of MS. Without synergistic effects (in absence of $\mathrm{TiO}_{2}-\mathrm{NP}$ ) the corrosion rate increased with long immersion time. These occurred when BPTA, molecules were being desorbed from MS coupons were exposed to $\mathrm{HCl}$ environment herewith increasing the contact of metalsolution that produce a dissolution of coupons surface. Without synergistic effects (in absence of $\mathrm{TiO}_{2}-\mathrm{NP}$ ) corrosion rate was increased after $10 \mathrm{~h}$, of immersion attributed to low inhibitor concentration in corrosive media to inhibit metal dissolution; it is evident that after BPTA, molecules were desorbed from the MS they were in-active so not take part in the inhibitive processes.

\subsubsection{Influence of temperature}

The gravimetrical technique was utilized to investigate the effect of solution temperature on the corrosive of MS in the absence and presence of BPTA molecules as a corrosion inhibitor and also the synergistic effect of BPTA molecules with $\mathrm{TiO}_{2}-\mathrm{NP}$. The results are shown in Figures 3 and 4. The results have been employed to find the activation energies of MS dissolution and Gibbs energies of adsorption of the BPTA, molecules as corrosion inhibitor on the surface of MS. The IE decreased with the increasing of temperature. On the other hand, no significant variation appears at the synergistic effect of BPTA molecules with $\mathrm{TiO}_{2}-\mathrm{NP}$, and after rising temperature the IE does not affected. The IE obtained at optimum inhibitor (BPTA) concentration with and without synergistic effect was 92 and $96 \%$ at $303.0 \mathrm{~K}$ and 41 and $60 \%$ at $333.0 \mathrm{~K}$ respectively, that the lowest and highest temperature that used in the present study. Inhibition efficiencies were decreased for the studied corrosion inhibitors with rising temperatures demonstrated the instability of synthesized inhibitors when they were undergoing to maximum studied temperatures. The BPTA, molecules as corrosion inhibitors at highest temperature were demonstrated from MS coupons which implied that the BPTA molecules adsorbed on the surface by an exothermic reaction, thereby releasing the heat at adsorption.

In the exothermic process, the rising temperature causes a reverse reaction. The opposite as well, true with endothermic process [43]. BPTA, molecules were found to act duly at low temperatures with low inhibition activities at higher temperatures, but the synergistic effects of BPTA with $0.001 \mathrm{~g}$, of $\mathrm{TiO}_{2}-\mathrm{NP}$, inhibit the corrosion process at low and high temperature. From Figures 5 and 6, the differences between corrosion rates for BPTA without and with the synergistic effects synthesized of $\mathrm{TiO}_{2}-\mathrm{NP}$.

\subsection{Adsorption isotherms}

Adsorption isotherm show data about the mechanism of inhibitor molecules that adsorbed by MS surface [44,45]. Adsorption of BPTA, molecules without and synergistic with $0.001 \mathrm{~g}$, of $\mathrm{TiO}_{2}-\mathrm{NP}$ on to the surface of MS are the primary step of the mechanism of adsorption. The significant parameter in the adsorption isotherm process is the surface coverage $(\theta)$ that may be estimated from the gravimetric technique as in equation 3 . 


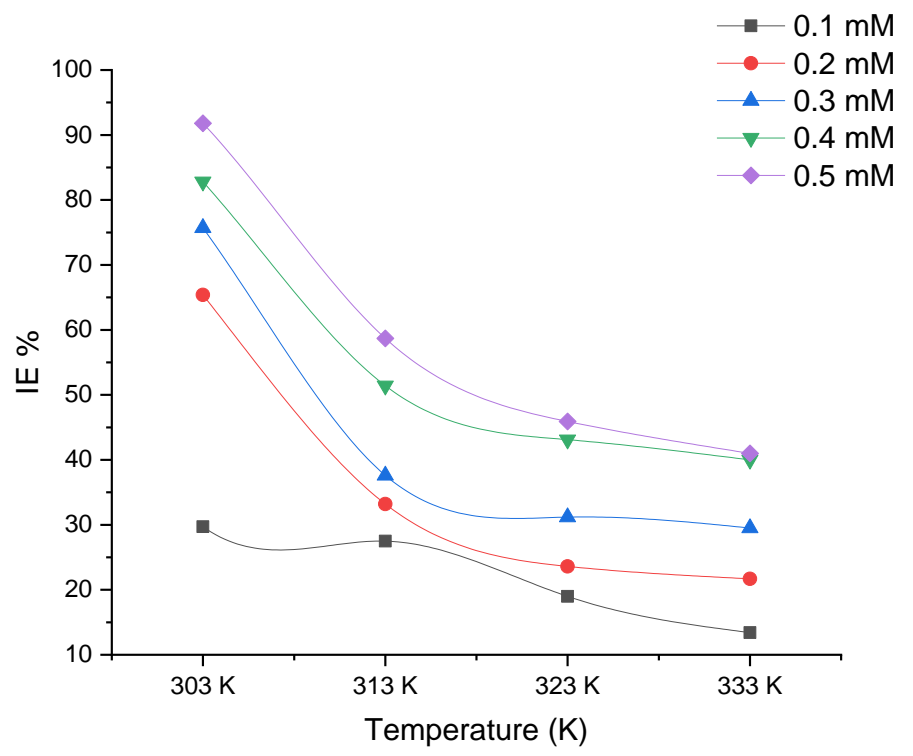

Figure 3. Effect of temperature on IE of BPTA in $1 \mathrm{M} \mathrm{HCl}$.

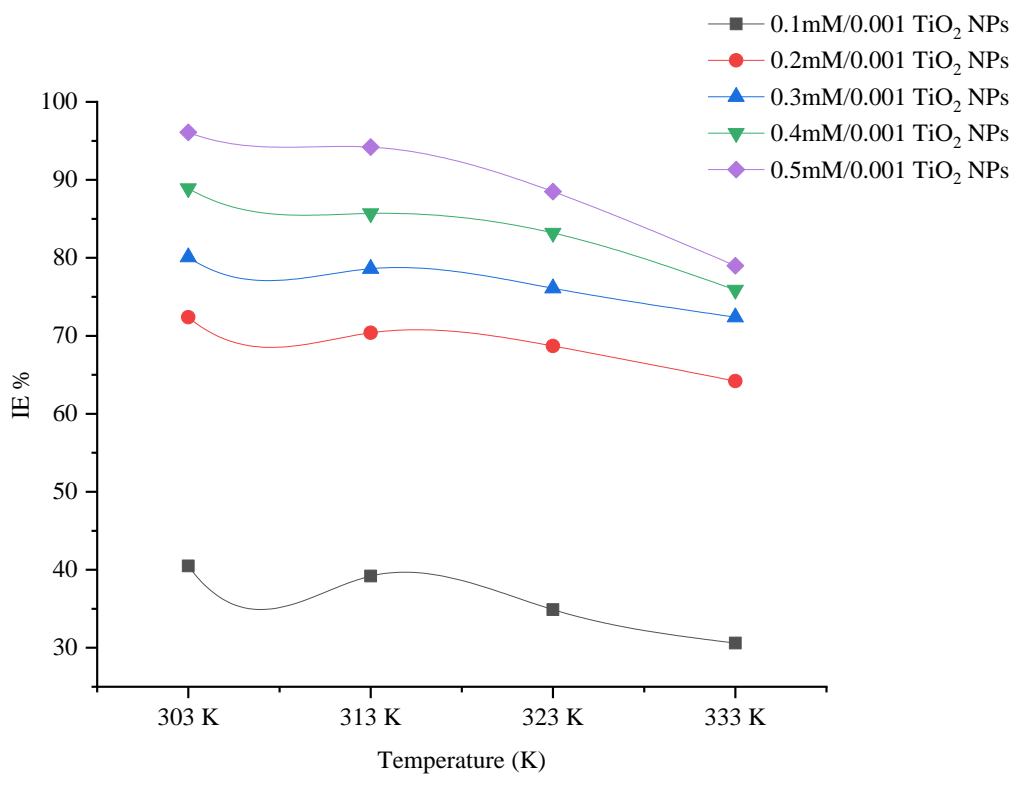

Figure 4. Temperature impact on inhibition efficiencies of BPTA synergistic with $0.001 \mathrm{~g}$, of $\mathrm{TiO}_{2}-\mathrm{NP}$ in $1 \mathrm{M} \mathrm{HCl}$. 


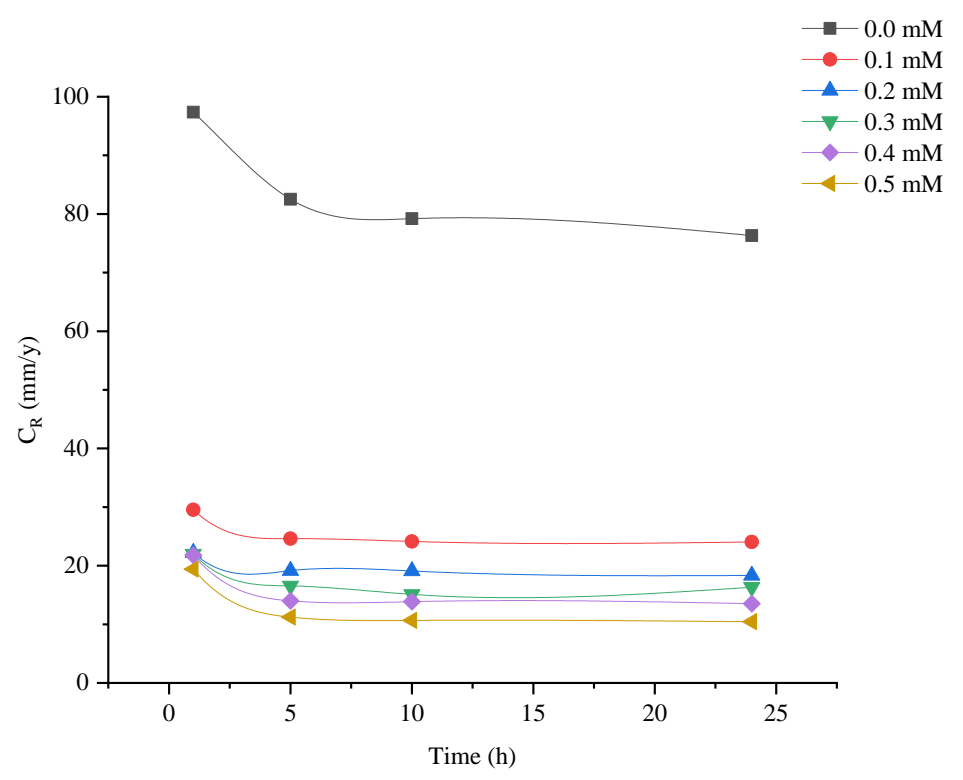

Figure 5. Impact of BPTA concentration and corrosion rate of MS with immersion time

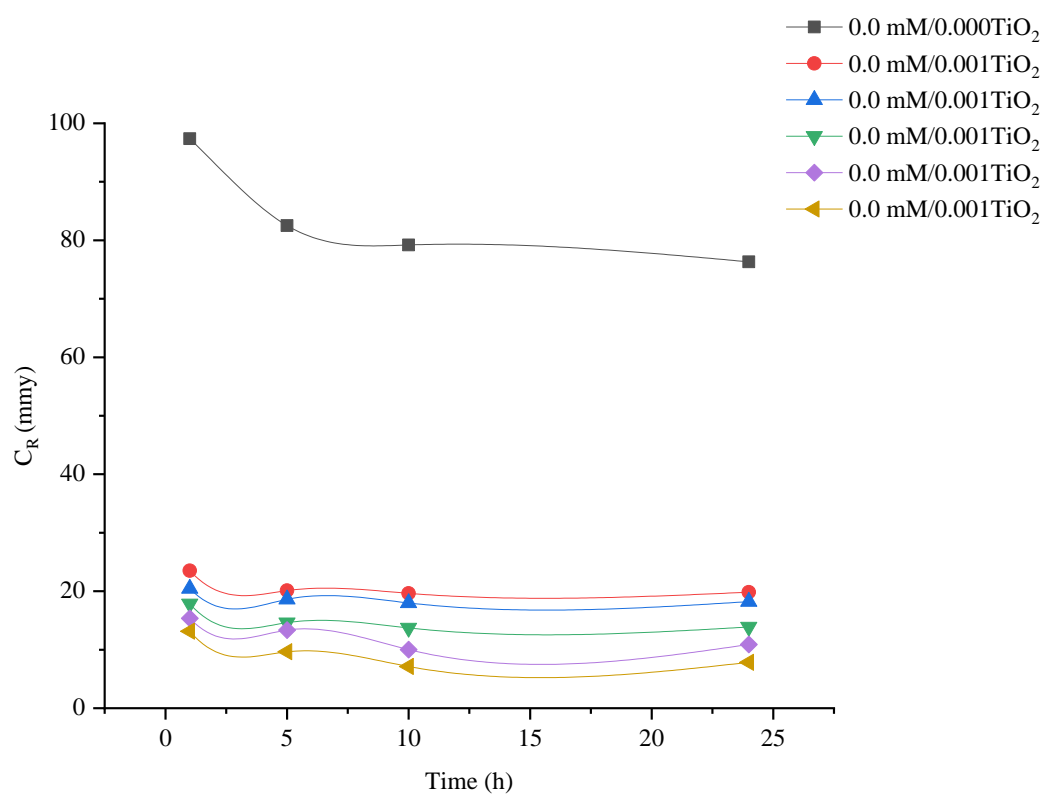

Figure 6. Influence of concentration of BPTA synergistic with $0.001 \mathrm{~g}$, of $\mathrm{TiO}_{2}-\mathrm{NP}$ in $1 \mathrm{M}$ $\mathrm{HCl}$ and time on the corrosion rate of MS.

Isotherms investigations demonstrate mechanism on how natural or organic molecules which used as inhibitor adsorb to the MS surface. The adsorption mechanism depends on some significant factors such as nature, electronic properties and charge of the MS surface in addition to solvent adsorption, ionic species, the electronic potential of metalenvironment interface and temperature of environment [46, 47]. Interaction of MS with organic molecules is higher than that of MS surface and $\mathrm{H}_{2} \mathrm{O}$ molecules, adsorption will 
occur. Langmuir adsorption model, Frumkin adsorption model and Temkin adsorption model were investigated and the fit model had been employed to calculate the thermodynamic parameters. The value of surface coverage increase with the concentration of tested inhibitors increase in corrosive solution; this was, imputed to form a layer of BPTA, without and synergistic with $0.001 \mathrm{~g}$, of $\mathrm{TiO}_{2}-\mathrm{NP}$ on to the surface of MS that reduces or impedance the corrosion of MS surface. Langmuir adsorption isotherm model was used to study the mechanism of adsorption. Equation 10 was utilized to estimate the equilibrium constant.

$$
\frac{C}{\theta}=\frac{1}{K_{\mathrm{ads}}}+B
$$

where $C$ is the concentration, $K_{\text {ads }}$ is the equilibrium constant and $B$ is an intercept.

Figure 7 presents the model plot of Langmuir for dissolution of MS that manifested to have correlation coefficients that were close to unity, that implied that the adsorption of inhibitor molecules on to MS surface supposed a one layer adsorption. The adsorption of tested inhibitor molecules on the MS surface obeyed Langmuir isotherm. For BPTA synergistic with $0.001 \mathrm{~g}$, of $\mathrm{TiO}_{2}-\mathrm{NP}$ on MS, Figure 8 represents the Langmuir plot for adsorption.

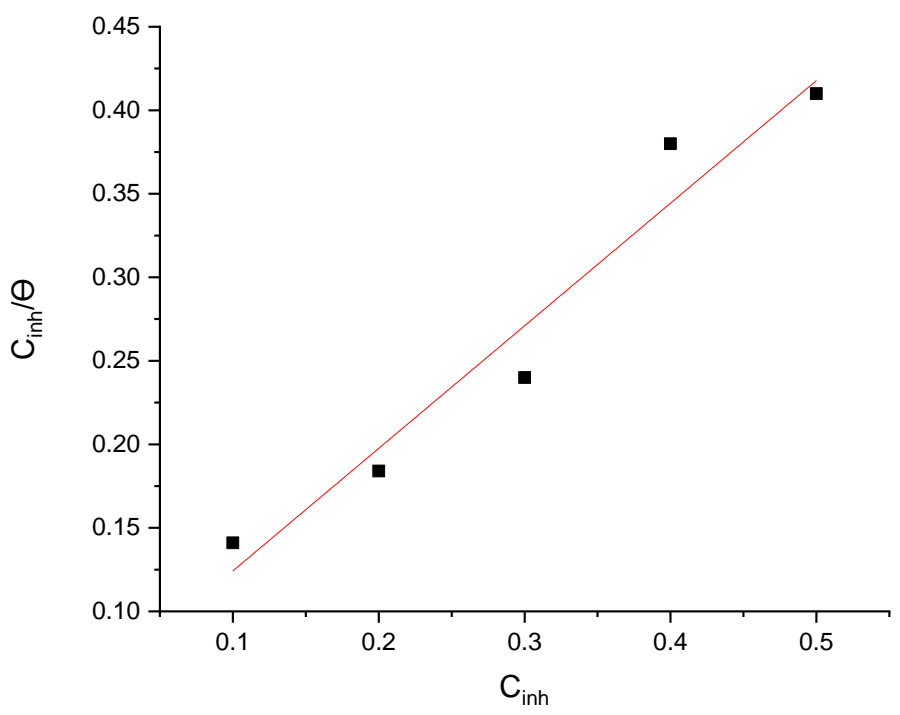

Figure 7. Langmuir plot of BPTA on MS. 


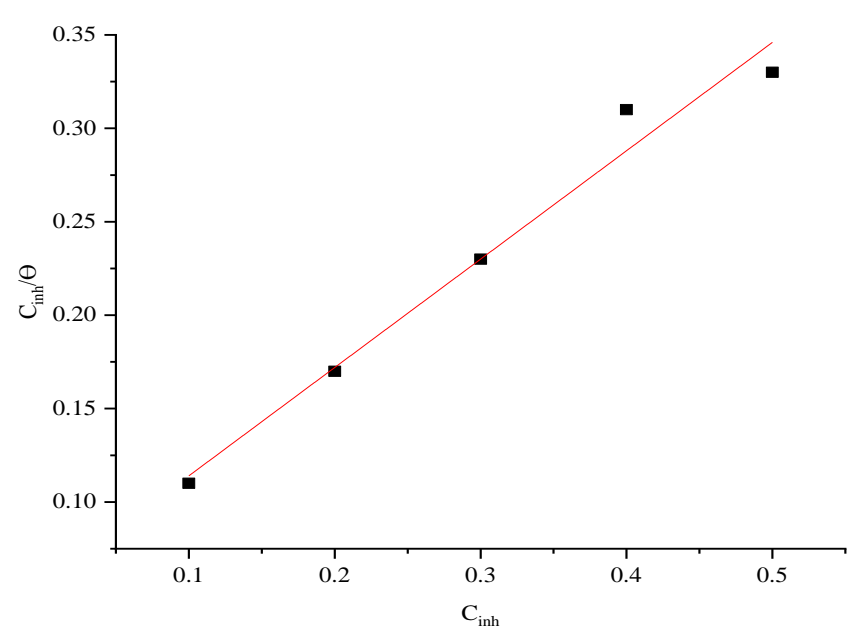

Figure 8. Langmuir plot for adsorption of corrosion inhibitor molecules of BPTA synergistic with $0.001 \mathrm{~g}$ of $\mathrm{TiO}_{2}-\mathrm{NP}$ on to MS.

\subsection{Quantum Chemistry}

In general, orbitals of HOMO and LUMO demonstrate the molecular regions that may give or accept electrons. The high value of HOMO orbital is facile to donate electrons to empty orbital of the iron atom. On the other hand, the low-value LUMO orbital expresses the ability to accept electrons from an iron atom. The optimized structures, HOMO and LUMO diagrams of BPTA and BPTA synergistic with $0.001 \mathrm{~g}$ of $\mathrm{TiO}_{2}-\mathrm{NP}$ molecules using Density Functional Theory are demonstrated in Figure 9. These were donating electron sites to unoccupied metal orbital. LUMO orbital for BPTA was found on all over the molecule whereas that of synergistic effect localized on the titanium and oxygen atoms. Thus, the HOMO and LUMO orbital analyses indicate that the thiadiazole ring, benzene ring and azomethine have a significant role in the interaction of the corrosive inhibitor with MS.

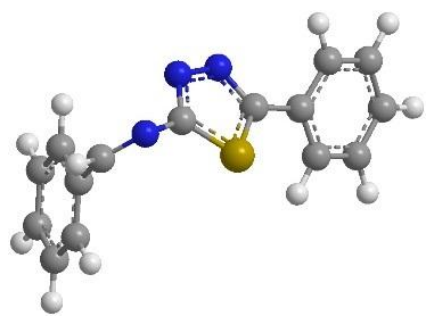

BPTA

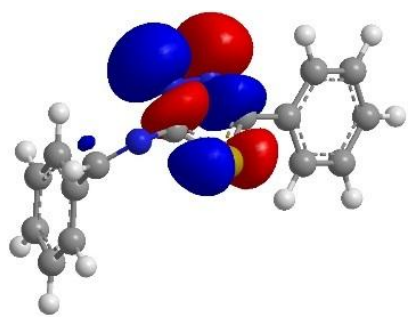

HOMO

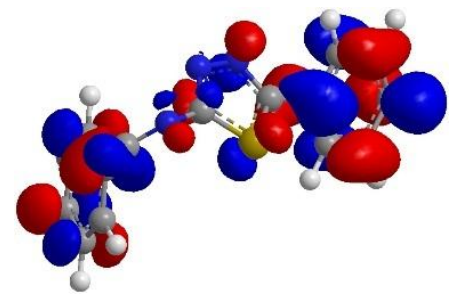

LUMO 


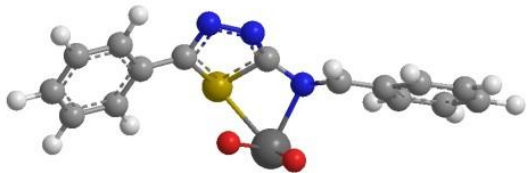

BPTA synergistic with $0.001 \mathrm{~g}$, of $\mathrm{TiO}_{2}-\mathrm{NP}$

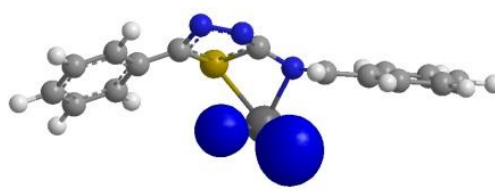

HOMO

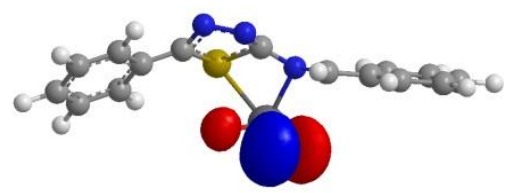

LUMO

Figure 9. Optimized structure, HOMO and LUMO orbitals distribution of BPTA and BPTA synergistic with $0.001 \mathrm{~g}$, of $\mathrm{TiO}_{2}-\mathrm{NP}$.

The parameters of the corrosion inhibitor BPTA and BPTA synergistic with $0.001 \mathrm{~g}$ of $\mathrm{TiO}_{2}-\mathrm{NP}$ and the average inhibition efficiencies (\%) were calculated and listed below in Table 1.

Table 1. Molecular characteristics of BPTA and BPTA synergistic with $0.001 \mathrm{~g}$, of $\mathrm{TiO}_{2}$-NPs.

\begin{tabular}{|c|c|c|c|c|c|c|}
\hline \multirow{2}{*}{ Inhibitor } & \multicolumn{3}{|c|}{ Energies in $\mathrm{eV}$} & \multirow{2}{*}{$\begin{array}{l}\text { Dipole } \\
\text { moment } \\
\text { (Debye) }\end{array}$} & \multirow{2}{*}{$\Delta N$} & \multirow{2}{*}{ IE\% } \\
\hline & $\boldsymbol{E}_{\text {номо }}$ & $\boldsymbol{E}_{\text {LUMO }}$ & $\Delta E$ & & & \\
\hline BPTA & -8.003 & -1.630 & 6.643 & 2.7 & 0.45 & 92 \\
\hline $\begin{array}{l}\text { BPTA synergistic with } \\
0.001 \mathrm{~g} \text {, of } \mathrm{TiO}_{2}-\mathrm{NPs}\end{array}$ & -11.430 & -9.954 & 1.476 & 0.573 & 0.49 & 96 \\
\hline
\end{tabular}

The relationship of inhibition efficiencies and HOMO energies levels for BPTA, and BPTA synergistic with $0.001 \mathrm{~g}$, of $\mathrm{TiO}_{2}-\mathrm{NP}$, were demonstrated in Table 1 . The inhibition efficiencies increased with the increasing of HOMO energies levels. In Table 1, inhibition efficiencies are against the LUMO energies, demonstrate that the IE decrease with the LUMO energies levels increases. The relationship between IE and the energy gap is negative (were demonstrated in Table 1).

Values of $\chi$ and $\eta$ as in Table 2, have been estimated utilizing the $I$ and $A$ calculated from theoretical calculations. The $\chi$ value of $7 \mathrm{eV} / \mathrm{mol}$ and the $\eta$ value of $0 \mathrm{eV} / \mathrm{mol}$ for iron atom [48], $\Delta N$, the fraction of electrons transferred from inhibitor molecules to the iron atoms, was estimated. The IE versus $\Delta N$ (presented in Table 1) clearly demonstrated that the IE increased with the $\Delta N$ increase. According to other reports [48, 49], values of $\Delta N$ showed that inhibition effect resulted from electrons donation. As agreed with the investigation of Lukovits [50], if $\Delta N<3.6$ the IE increased with increase ability electrondonating at the iron surface. In this study, the BPTA and BPTA synergistic with $0.001 \mathrm{~g}$, of $\mathrm{TiO}_{2}-\mathrm{NP}$ were the donators of electrons, and the iron surface was the acceptor. BPTA and 
BPTA synergistic with $0.001 \mathrm{~g}$, of $\mathrm{TiO}_{2}-\mathrm{NP}$, were bound to the MS surface and thus formed an inhibition adsorption layer against corrosion.

The structure of the molecules can affect the adsorption by influencing the electron density at the functional group. Generally, electrophiles attack the molecules at negatively charged sites. The regions of the highest electron density are generally the sites in which electrophiles attacked. So $\mathrm{N}$ and $\mathrm{S}$ atoms were the active center, which had the strongest ability of bonding to the metal surface.

Based on the discussion above, it can be concluded that the BPTA synergistic with $0.001 \mathrm{~g}$, of $\mathrm{TiO}_{2}-\mathrm{NP}$, has many active centers of negative charge. In addition, the areas containing $\mathrm{N}$ and $\mathrm{S}$ atoms in addition to the two oxygen atoms of $\mathrm{TiO}_{2}$ are the most possible sites of bonding metal surface by donating electrons to the metal iron.

Table 2. The quantum chemical parameters for BPTA and BPTA synergistic with $0.001 \mathrm{~g}$, of $\mathrm{TiO}_{2}-\mathrm{NPs}_{\text {. }}$

\begin{tabular}{|c|c|c|}
\hline Function & BPTA & Synergistic \\
\hline$I=-E_{\text {НОмО }}$ & 8.003 & 11.430 \\
\hline$A=-E_{\mathrm{LUMO}}$ & 1.630 & 9.954 \\
\hline$\eta=-0.5\left(E_{\text {номо }}-E_{\text {LUмо }}\right)$ & 3.321 & 0.738 \\
\hline$\sigma=1 / \eta$ & 0.30111 & 1.3550 \\
\hline$\chi=-0.5\left(E_{\text {номо }}+E_{\text {LUмо }}\right)$ & 4.8165 & 10.692 \\
\hline
\end{tabular}

\subsection{Mechanism of corrosion inhibition}

Determination of the adsorption is the major significant aspect in the mechanism investigations of corrosion inhibitor actions [51]. Corrosion inhibition mechanism of BPTA and BPTA synergistic with $0.001 \mathrm{~g}$, of $\mathrm{TiO}_{2}-\mathrm{NP}$ in corrosive environment was demonstrated by the adsorption of BPTA and BPTA synergistic with $0.001 \mathrm{~g}$, of $\mathrm{TiO}_{2}-\mathrm{NP}$ molecules onto the MS surface. The inhibition efficiencies of the BPTA and BPTA synergistic with $0.001 \mathrm{~g}$, of $\mathrm{TiO}_{2}-\mathrm{NP}$ are related to considerable factors such as alloy type, acidic environment, structure of inhibitor including adsorption centers sites, electronic structure, and inhibitor chemical characteristics, interactions type between inhibitor molecules and MS surface [52]. The obtained results (experiments and theoretical), adsorption, different inhibitor molecules may be adsorbed at different sites on the surface of MS. Chemically the inhibitors are adsorbed on MS surface and form protective layers or coordinated bonds through reaction of inhibitor molecules and MS surface. The adsorption mechanism of organic inhibitor molecules can proceed through these ways, 1st, electrostatically attract of charged molecules with MS. 2nd, reaction of unpaired electrons with the MS surface. 3rd, reaction of $\pi$-electrons with MS surface. The inhibition efficiencies of BPTA and BPTA synergistic with $0.001 \mathrm{~g}$, of $\mathrm{TiO}_{2}-\mathrm{NP}$ may be demonstrated according to the adsorption sites number, charge density, molecular size, 
mode of interaction with the MS surface and capability to form coordination complex. The $\pi$-electrons of double bonds and unshared electrons on the sulfur and nitrogen atoms form chemical bonds with the MS surface as demonstrated in Figure 10.

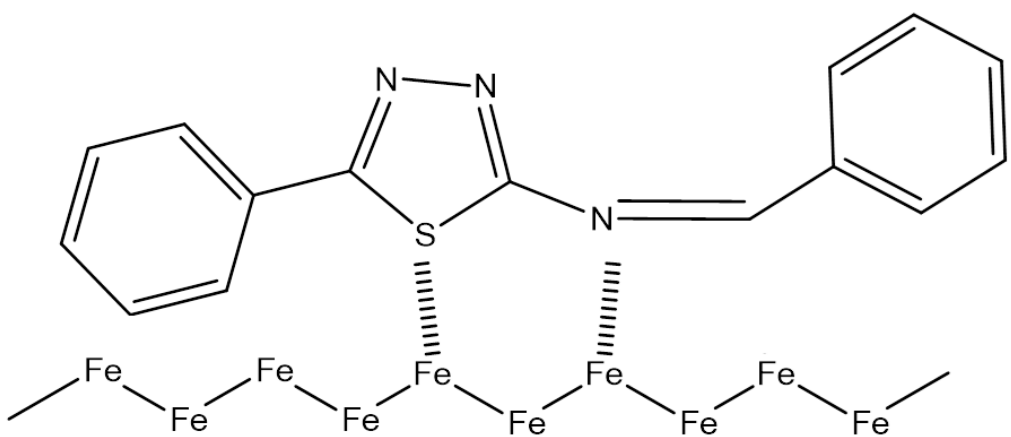

Figure 10. Suggested mechanism of action of the BPTA.

The oxygen atoms of $\mathrm{TiO}_{2}$ in addition to $\pi$-bonds and unshared electrons on the $\mathrm{S}$ and $\mathrm{N}$ atoms with the MS as demonstrated in Figure 11.

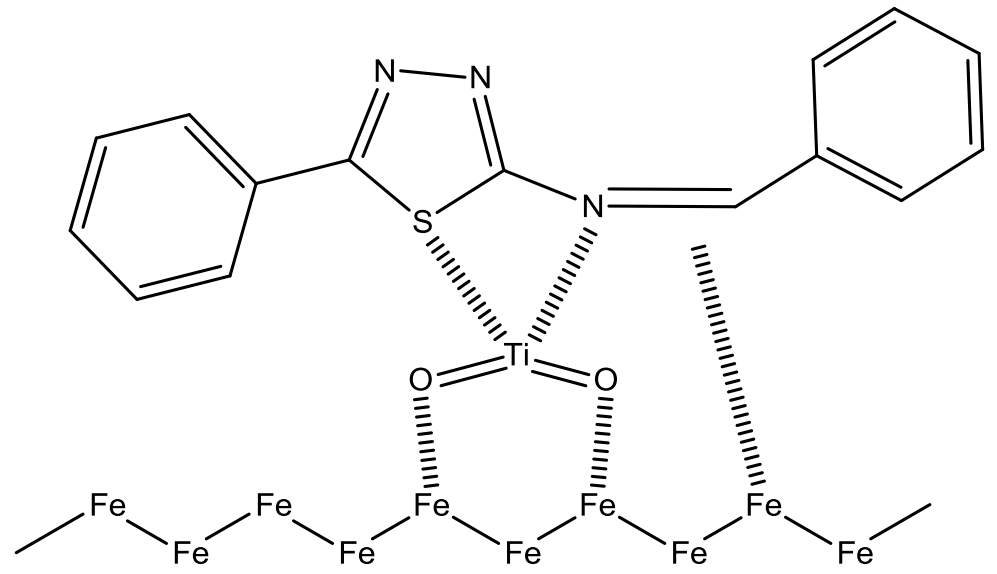

Figure 11. The suggested mechanism of action of the synergistic BPTA with $\mathrm{TiO}_{2}-\mathrm{NP}$.

\subsection{Characterization of $\mathrm{TiO}_{2}$}

\section{$X$-Ray characterization}

The crystal structure, crystallinity and crystalline size for the synthesized NPs were done by (XRD; Bruker axs D8) using $\mathrm{CuK} \alpha(\lambda=0.15406 \mathrm{~nm})$ radiation. Figure 12 shows the XRD pattern of the prepared $\mathrm{TiO}_{2}-\mathrm{NP}$. The diffraction peaks appeared at $2 \theta=26.04^{\circ}$, $42.95^{\circ}$ and $57.03^{\circ}$, these angles were assigned to (100), (101) and (111) planes. The diffraction peaks at these angles indicating that $\mathrm{TiO}_{2}$ was in the anatase phase. The intense XRD peak of the prepared sample indicates that the NPs were crystalline while the broad peaks indicated small crystalline size. There was a slight shift in $2 \theta$ values, this shift confirmed that the NP positioned at the higher angles have a slightly larger particle size 
than that appeared at lower angles. The crystalline size (D) of the prepared $\mathrm{TiO}_{2} \mathrm{NP}$ was calculated by Debye-Scherer equation 11:

$$
D=\frac{k \lambda}{\beta \cos \theta}
$$

Where $k=0.9$ is a dimensionless geometric factor that accounts for the particle shape, $\beta$ is the full width at half maximum (FWHM) of the most intense peak and $\theta$ is the diffraction angle.

According to the XRD data, the particle size of the synthesized $\mathrm{TiO}_{2}-\mathrm{NP}$ was found to be $13 \mathrm{~nm}$. These investigations are agreeing with previous reports [53].

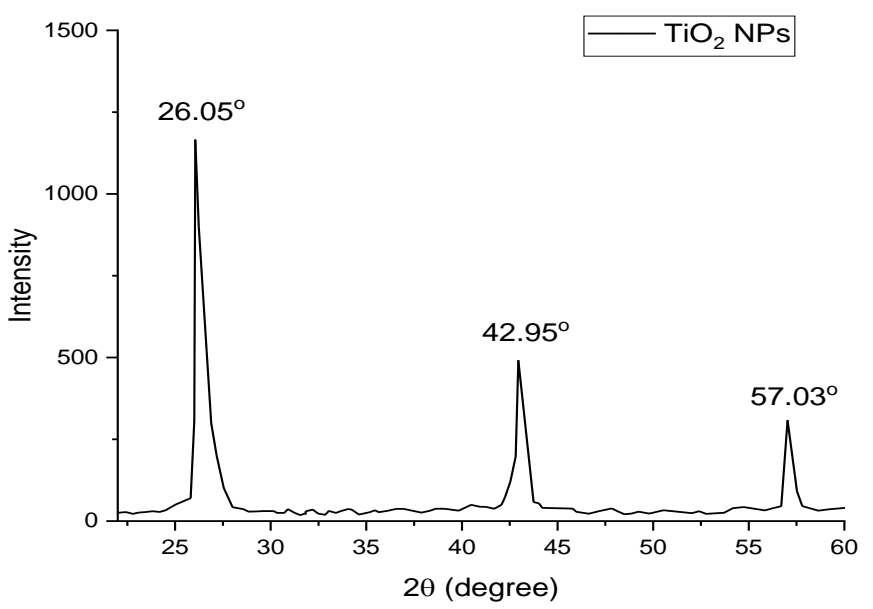

Figure 12: The $\mathrm{X}$-ray characterization of $\mathrm{TiO}_{2}-\mathrm{NP}$.

\section{Conclusions}

In this study, a benzylidene derivative with $\pi$ electron-rich aromatic rings namely BPTA has been synthesized and characterized using FTIR, NMR and elemental analyzer. $\mathrm{TiO}_{2^{-}}$ NP were also synthesized and characterized by XRD. The inhibition impact of the synthesized inhibitor BPTA and BPTA synergistic with $\mathrm{TiO}_{2}-\mathrm{NP}$ for MS in the corrosive environment was evaluated utilizing weight loss. Theoretical investigations were performed to evaluate the adsorption or binding of the synthesized inhibitor molecules onto the MS surface. The synergy of BPTA with $\mathrm{TiO}_{2}$-NP exhibited a superior IE. Corrosion impedance efficiency was found to depend on the BPTA concentration and the solution temperature. Results from the experimental and theoretical considerations are in good agreement confirming that BPTA synergy with $\mathrm{TiO}_{2}-\mathrm{NP}$ is a better corrosion inhibitor than BPTA alone.

\section{Conflicts of interest}

There are no conflicts to declare. 


\section{References}

1. E. Osarolube, I. Owate and N. Oforka, Corrosion behaviour of mild and high carbon steels in various acidic media, Sci. Res. Essay, 2008, 3, 224-228.

2. M. Fontana and N. Greene, Corrosion Engineering, McGraw-Hill book Company, New York, 1987, pp. 8-29.

3. K. Babić-Samardžija, K. Khaled and N. Hackerman, N-heterocyclic amines and derivatives as corrosion inhibitors for iron in perchloric acid, Anti-Corros. Meth. Mater., 2005, 52, no. 1, 11-21. doi: 10.1108/00035590510574871

4. E. Oguzie, Inhibition of acid corrosion of mild steel by Telfaria occidentalis extract, Pigm. Resin Technol., 2005, 34, 321-326.

5. M. Abdallah, Guar gum as corrosion inhibitor for carbon steel in sulfuric acid solutions, Port. Electrochim. Acta, 2004, 22, 161-175.

6. S. Africa, Adsorption and inhibitive properties of ethanol extracts of Musa sapientum peels as a green corrosion inhibitor for mild steel in $\mathrm{H}_{2} \mathrm{SO}_{4}$, Afr. J. Pure Appl. Chem., 2008, 2, 46-54.

7. G. Grivani, G. Bruno, H. Rudbari, A. Khalaji and P. Pourteimouri, Synthesis, characterization and crystal structure determination of a new oxovanadium (IV) Schiff base complex: the catalytic activity in the epoxidation of cyclooctene, Inorg. Chem. Commun., 2012, 18, 15-20.

8. Ö. Güngör and P. Gürkan, Synthesis and characterization of higher amino acid Schiff bases, as monosodium salts and neutral forms. Investigation of the intramolecular hydrogen bonding in all Schiff bases, antibacterial and antifungal activities of neutral forms, J. Mol. Struct., 2014, 1074, 62-70.

9. F. Dong, J. Zhang, C. Yu, Q. Li, J. Ren, G. Wang, G. Gu and Z. Guo, Synthesis of amphiphilic aminated inulin via 'click chemistry' and evaluation for its antibacterial activity, Bioorg. Med. Chem. Lett., 2014, 24, no. 18, 4590-4593. doi: 10.1016/j.bmcl.2014.07.029

10. S. Junaedi, A. Kadhum, A. Al-Amiery, A. Mohamad and M. Takriff, Synthesis and characterization of novel corrosion inhibitor derived from oleic acid: 2-Amino-5-Oleyl1,3,4-Thiadiazol (AOT), Int. J. Electrochem. Sci., 2012, 7, 3543-3554.

11. A.A. Al-Amiery, A.A.H. Kadhum, A.B. Mohamad and S. Junaedi, A Novel Hydrazinecarbothioamide as a Potential Corrosion Inhibitor for Mild Steel in $\mathrm{HCl}$, Materials, 2013, 6, no. 4, 1420-1431. doi: 10.3390/ma6041420

12. A.A. Al-Amiery, A.A.H. Kadhum, A.B. Mohamad, A.Y. Musa and C.J. Li, Electrochemical study on newly synthesized chlorocurcumin as an inhibitor for mild steel corrosion in hydrochloric acid, Materials, 2013, 6, no. 12, 5466-5477. doi: 10.3390/ma6125466

13. A.A.H. Kadhum, A.B. Mohamad, L.A. Hammed, A.A. Al-Amiery, N.H. San and A.Y. Musa, Inhibition of Mild Steel Corrosion in Hydrochloric Acid Solution by New Coumarin, Materials, 2014, 7, no. 6, 4335-4348. doi: 10.3390/ma7064335 
14. A.A. Al-Amiery, A.A.H. Kadhum, A. Kadihum, A.B. Mohamad, C.K. How and S. Junaedi, Inhibition of Mild Steel Corrosion in Sulfuric Acid Solution by New Schiff Base, Materials, 2014, 7, no. 2, 787-804. doi: 10.3390/ma7020787

15. A.A. Al-Amiery, A.A.H. Kadhum, A.H.M. Alobaidy, A.B. Mohamad and P.S. Hoon, Novel Corrosion Inhibitor for Mild Steel in HCl, Materials, 2014, 7, no. 2, 662-672. doi: http://dx.doi.org/10.3390/ma7020662

16. S.B. Al-Baghdadi, F.G. Hashim, A.Q. Salam, T.K. Abed, T.S. Gaaz, A.A. Al-Amiery, A.A.H. Kadhum, K.S. Reda and W.K. Ahmed, Synthesis and corrosion inhibition application of NATN on mild steel surface in acidic media complemented with DFT studies, Results Phys., 2018, 8, 1178-1184. doi: 10.1016/j.rinp.2018.02.007

17. H.J. Habeeb, H.M. Luaibi, R.M. Dakhil, A.A.H. Kadhum, A.A. Al-Amiery and T.S. Gaaz, Development of new corrosion inhibitor tested on mild steel supported by electrochemical study, Results Phys., 2018, 8, 1260-1267. doi: 10.1016/j.rinp.2018.02.015

18. K.F. Al-Azawi, I.M. Mohammed, S.B. Al-Baghdadi, T.A. Salman, H.A. Issa, A.A. AlAmiery, T.S. Gaaz and A.A.H. Kadhum, Experimental and quantum chemical simulations on the corrosion inhibition of mild steel by 3-((5-(3,5-dinitrophenyl)1,3,4-thiadiazol-2-yl)imino)indolin-2-one, Results Phys., 2018, 9, 278-283. doi: 10.1016/j.rinp.2018.02.055

19. A.B. Mohamad, A.A.H. Kadhum, A. Al-Amiery, L.C. Ying and A. Musa, Synergistic of a coumarin derivative with potassium iodide on the corrosion inhibition of aluminum alloy in $1.0 \mathrm{M} \mathrm{H}_{2} \mathrm{SO}_{4}$, Met. Mater. Int., 2014, 20, 459-467. doi: $\underline{10.1007 / \mathrm{s} 12540-014-3008-3}$

20. H.R. Obayes, G.H. Alwan, A.H.MJ. Alobaidy, A. Al-Amiery, A.A.H. Kadhum and A.B. Mohamad, Quantum chemical assessment of benzimidazole derivatives as corrosion Inhibitors, Chem. Cent. J., 2014, 8, Article 21, 1-8. doi: 10.1186/1752$\underline{153 X-8-21}$

21. A.A. Al-Amiery, Y.K. Al-Majedy, A.A.H. Kadhum and A.B. Mohamad, New Coumarin Derivative as an Eco-Friendly Inhibitor of Corrosion of Mild Steel in Acid Medium, Molecules, 2015, 20, no. 1, 366-383. doi: 10.3390/molecules20010366

22. E. Yousif, Y.-F. Win, A.H. Al-Hamadani, A. Al-Amiery, A.A.H. Kadhum and A.B. Mohamad, Furosemide as an environmental-friendly inhibitor of corrosion of zinc metal in acid medium: Experimental and theoretical studies, Int. J. Electrochem. Sci., $2015, \mathbf{1 0}, 1708-1718$.

23. S.B. Al-Baghdadi, F.T.M. Noori, W.K. Ahmed and A.A. Al-Amiery, Thiadiazole as a Potential Corrosion Inhibitor for Mild Steel in $1 \mathrm{M} \mathrm{HCl}, J$. Adv. Electrochem., 2016, 2, $67-69$.

24. A.A. Al-Amiery, F.A.B. Kassim, A.A.H. Kadhum and A.B. Mohamad, Synthesis and characterization of a novel eco-friendly corrosion inhibition for mild steel in $1 \mathrm{M}$ hydrochloric acid, Sci. Rep., 2016, 6. doi: 10.1038/srep19890 
25. A. Kadhim, A.K. Al-Okbi, D.M. Jamil, A. Qussay, A.A. Al-Amiery, T.S. Gaas, A.A.H. Kadhum, A.B. Mohamad and M.H. Nassir, Experimental and theoretical studies of benzoxazines corrosion inhibitors, Results Phys., 2017, 7, 4013-4019. doi: 10.1016/j.rinp.2017.10.027

25. H.R. Obayes, A.A. Al-Amiery, G.H. Alwan, T.A. Abdullah, A.A.H. Kadhum and A.B. Mohamad, Sulphonamides as corrosion inhibitor: experimental and DFT studies, J. Mol. Struct., 2017, 1138, 27-34. doi: 10.1016/j.molstruc.2017.02.100

26. H.R. Obayes, A.A. Al-Amiery, G.H. Alwan, T.A. Abdullah, A.A.H. Kadhum and A.B. Mohamad, Sulphonamides as corrosion inhibitor: experimental and DFT studies, J. Mol. Struct., 2017, 1138, 27-34. doi: /10.1016/j.molstruc.2017.02.100

27. D.M. Jamil, A.K. Al-Okbi, S.B. Al-Baghdadi, A.A. Al-Amiery, A. Kadhim and T.S. Gaaz, Experimental and theoretical studies of Schiff bases as corrosion inhibitors, Chem. Cent. J., 2018, 12, 1-7. doi: 10.1186/s13065-018-0376-7

28. M.H.O. Ahmed, A.A. Al-Amiery, Y.K. Al-Majedy, A.A.H. Kadhum, A.B. Mohamad and T.S. Gaaz, Synthesis and characterization of a novel organic corrosion inhibitor for mild steel in $1 \mathrm{M}$ hydrochloric acid, Results Phys., 2018, 8, 728-733. doi: 10.1016/j.rinp.2017.12.039

29. T.A. Salman, D.S. Zinad, S.H. Jaber, M. Shayaa, A. Mahal, M.S. Takriff and A.A. AlAmiery, Effect of 1,3,4 Thiadiazole Scafold on the Corrosion Inhibition of Mild Steel in Acidic Medium: An Experimental and Computational Study, J. Bio Tribo-Corros., 2019, 5, 1-11. doi: 10.1007/s40735-019-0243-7

30. D. Mahmood, A.K. Al-Okbi, M.M. Hanon, K.S. Rida, A.F. Alkaim, A.A. Al-Amiery, A. Kadhum and A.A.H. Kadhum, Carbethoxythiazole corrosion inhibitor: As an experimentally model and DFT theory, J. Eng. Appl. Sci., 2018, 13, 3952-3959. doi: 10.3923/jeasci.2018.3952.3959

31. A.Y.I. Rubaye, K.S. Rida, A.Q. Salam and A. Al-Amiery, Acetamidocoumarin as a based eco-friendly corrosion inhibitor, Int. J. Chem Tech Res., 2016, 9, no. 11, 39-47.

32. H.J. Habeeb, H.M. Luaibi, T.A. Abdullah, R.M. Dakhil, A.A.H. Kadhum and A.A. AlAmiery, Case study on thermal impact of novel corrosion inhibitor on mild steel, Case Stud. Therm. Eng., 2018, 12, 64-68. doi: 10.1016/j.csite.2018.03.005

33. V. Purcar, V. Rădiţoiu, A. Dumitru, C.-A. Nicolae, A.N. Frone, M. Anastasescu, A. Rădiţoiu, M.F. Radulya, R.A. Gabor and S. Căprărescu, Antireflective coating based on $\mathrm{TiO}_{2}$ nanoparticles modified with coupling agents via acid-catalyzed sol-gel method, Appl. Surf. Sci., 2019, 487, 819-824. doi: 10.1016/j.apsusc.2019.02.256

34. B. Valdez, Corrosion Tests and Standards: Applications and Interpretation, Corrosion, 2006, 62, 280.

35. R. Baboian, Corrosion tests and standards: application and interpretation, 1995, ASTM international.

36. T.A. Salman, A.A. Al-Amiery, L.M. Shaker, A.A.H. Kadhum and M.S. Takriff, A study on the inhibition of mild steel corrosion in hydrochloric acid environment by 4 - 
methyl-2-(pyridin-3-yl)thiazole-5-carbohydrazide, Int. J. Corros. Scale Inhib., 2019, 8, no. 4, 1035-1059. doi: 10.17675/2305-6894-2019-8-4-14

37. S. Şafak, B. Duran, A. Yurt and G. Türkoğlu, Schiff bases as corrosion inhibitor for aluminium in $\mathrm{HCl}$ solution, Corros. Sci., 2012, 54, 251-259.

38. M. Frisch et al., Gaussian 03, revision C. 02, Gaussian, Inc., Wallingford, ct 26, 2004.

39. I. Ahamad, R. Prasad and M. Quraishi, Experimental and quantum chemical characterization of the adsorption of some Schiff base compounds of phthaloyl thiocarbohydrazide on the mild steel in acid solutions, Mater. Chem. Phys., 2010, 124, 1155-1165.

40. M. Lashgari, M. Arshadi and G. Parsafar, A simple and fast method for comparison of corrosion inhibition powers between pairs of pyridine derivative molecules, Corrosion, 2005, 61, 778-783.

41. J. Wang, Z. Lian, H. Wang, X. Jin and Y. Liu, Synthesis and antimicrobial activity of Schiff base of chitosan and acylated chitosan, J. Appl. Polym. Sci., 2012, 123, 32423247.

42. T.A. Salman, Q.A. Jawad, M.A.M. Hussain, A.A. Al-Amiery, L. Mohamed, A.A.H. Kadhum and M.S. Takriff, Novel ecofriendly corrosion inhibition of mild steel in strong acid environment: Adsorption studies and thermal effects, Int. J. Corros. Scale Inhib., 2019, 8, no. 4, 1123-1137. doi: 10.17675/2305-6894-2019-8-4-19

43. M. Benabdellah, K. Khaled and B. Hammouti, Kinetic investigation of C38 steel corrosion in concentrated perchloric acid solutions, Mater. Chem. Phys., 2010, 120, 61-64.

44. Q.A. Jawad, D.S. Zinad, R.D. Salim, A.A. Al-Amiery, T.S. Gaaz, M.S. Takriff and A.H. Kadhum, Synthesis, Characterization, and Corrosion Inhibition Potential of Novel Thiosemicarbazone on Mild Steel in Sulfuric Acid Environment, Coatings, 2019, 9, 729. doi: $10.3390 /$ coatings9110729

45. A. Sabirneeza and S. Subhashini, A novel water-soluble, conducting polymer composite for mild steel acid corrosion inhibition, J. Appl. Polym. Sci., 2013, 127, 3084-3092.

46. A. Biswas, S. Pal and G. Udayabhanu, Experimental and theoretical studies of xanthan gum and its graft co-polymer as corrosion inhibitor for mild steel in $15 \% \mathrm{HCl}, \mathrm{Appl}$. Surf. Sci., 2015, 353, 173-183.

47. I. Adejoro, F. Ojo and S. Obafemi, Corrosion inhibition potentials of ampicillin for mild steel in hydrochloric acid solution, J. Taibah Univ. Sci., 2015, 9, 196-202.

48. N. Obi-Egbedi, I. Obot and S. Umoren, Spondias mombin L. as a green corrosion inhibitor for aluminium in sulphuric acid: Correlation between inhibitive effect and electronic properties of extracts major constituents using density functional theory, Arab. J. Chem., 2012, 5, 361-373.

49. I. Lukovits, E. Kalman and F.Zucchi, Corrosion inhibitors-correlation between electronic structure and efficiency, Corrosion, 2001, 57, 3-8. 
50. D. Gurudatt, and K. Mohana, Synthesis of new pyridine based 1,3,4-oxadiazole derivatives and their corrosion inhibition performance on mild steel in $0.5 \mathrm{M}$ hydrochloric acid, Ind. Eng. Chem. Res., 2014, 53, 2092-2105.

51. Yu.I. Kuznetsov, N.N. Andreev and S.S. Vesely, Why we reject papers with calculations of inhibitor adsorption based on data on protective effects, Int. J. Corros. Scale Inhib., 2015, 4, no. 2, 108-109.

52. D. Gopi et al., Corrosion and corrosion inhibition of mild steel in groundwater at different temperatures by newly synthesized benzotriazole and phosphono derivatives. Ind. Eng. Chem. Res., 2014, 53, 4286-4294.

53. K. Thamaphat, P. Limsuwan and B. Ngotawornchai, B. Phase characterization of $\mathrm{TiO}_{2}$ powder by XRD and TEM, Kasetsart J. (Nat. Sci.), 2008, 42, 357-361. 